\title{
PENGARUH PERSEPSI GENERASI Y TERHADAP PILIHAN KARIR PADA MAHASISWA PROGRAM STUDI MANAJEMEN UNIVERSITAS AHMAD DAHLAN
}

\author{
Adeliyanti \\ adeliyanti8@gmail.com \\ Universitas Ahmad Dahlan \\ Rikha Muftia Khoirunnisa \\ move.tya@gmail.com \\ Universitas Ahmad Dahlan
}

\begin{abstract}
ABSTRAK
This study aims at finding out the influence of the perception of generation $\mathrm{Y}$ (consideration of job market, career motivation, family influence, social value of job, and career lifestyle) on career choice in students of Management Study Program of Ahmad Dahlah University. The population of the study was students of Management Study Program of Ahmad Dahlan University of class 2015. The sample collecting technique used was purposive sampling, with a sample critrion of those who took thesis subject with a total og 212 students. The data analysis used in the study was multiple linear regression analysis. The findings of the study show that the career motivation and socual value of the job significantly influenced career choice in students of Management Study Program of Ahmad Dahlan Unversity, while the consideration of job market, family influence and career lifestyle did not significantly influence career choice in students of Management Study Program of Ahmad Dahlan Unversity. Futhermore, through F test, is showed that the consideration of job market, career motivation, family influence the social value of job and career lifestyle simultaneously significantly influenced career choice in students of Management Study Program of Ahmad Dahlan University. The R square calue obtained was 0,772. This, it can be interpreted that the influence contribution of the independent variables (consideration of job market (X1), career motivation (X2), family influence (X3), social value of job (X4) and career lifestyle (X5) on the dependent variable career choice (Y) was $77,2 \%$, while the other $22,8 \%$ can be explained by other variables that were not observed in this study.
\end{abstract}

Keywords: Consideration of Job Market, Career Motivation, Family Influence, Social Value of Job, Career Lifestyle, Career Choice.

\begin{tabular}{l}
\hline \multicolumn{3}{c}{ PENDAHULUAN } \\
\hline Sumber daya manusia adalah \\
komponen yang sangat penting perannya \\
dalam pembangunan ekonomi nasional. \\
Persaingan global yang ketat, \\
perkembangan teknologi yang pesat, \\
perubahan demografi, fluktuasi ekonomi \\
dan kondisi dinamis lain, mengharuskan \\
setiap sumber daya manusia dapat \\
beradaptasi dan bertumbuh kembang \\
dalam lingkungan yang berkemajuan
\end{tabular}

seperti saat ini. Menurut Prabowo (2016), tatanan baru masyarakat Indonesia dihadapkan pada harapan dan tantangan global yang dipicu oleh kemajuan dibidang ilmu pengetahuan informasi dan teknologi, transportasi serta perdagangan. Kondisi tersebut di ikuti pergeseran pola pikir generasi sekarang, yang perlu disikapi dengan bijak oleh setiap individu, dunia pendidikan, industri maupun pemerintah. 
Pesatnya peningkatan taraf pendidikan di Indonesia serta pertumbuhan ekonomi membuat dunia bisnis menyediakan lapangan kerja yang beranekaragam untuk angkatan kerja. Selain itu, sumber daya manusia yang berkualitas semakin banyak dibutuhkan dalam berbagai bidang karier. Maka, peran perguruan tinggi sangatlah penting dalam mencetak lulusan-lulusan sumber daya manusia yang berkompeten untuk dapat memenuhi kebutuhan posisi kerja yang beranekaragam tersebut serta mampu bersaing dengan sumber daya manusia lain, baik di domestik maupun internasional.

Dalam dunia pendidikan nasional, khususnya pendidikan perguruan tinggi, Daerah Istimewa Yogyakarta dijuluki sebagai "Kota Pelajar" dimana dari data statistik pendidikan tinggi yang diterbitkan oleh Dikti tahun 2017, terdaftar terdapat 112 perguruan tinggi di Yogyakarta, tercatat Daerah Istimewa Yogyakarta termasuk dalam urutan 6 daerah teratas di Indonesia yang paling banyak meluluskan mahasiswa dari perguruan tinggi berjumlah 59.634 lulusan pada tahun 2017.

Salah satu universitas swasta ternama yang banyak memberikan sumbangsih lulusan yang berkualitas diantaranya adalah Universitas Ahmad Dahlan yang beberapa tahun terakhir ini berkembang sangat pesat mulai dari pengadaan infrastruktur universitas yang berskala internasional hingga peningkatan akreditasi universitas yang kini berakreditasi A. Untuk jumlah mahasiswa UAD pada tahun ajaran 2017/2018 tercatat dalam website Forlap Ristek Dikti yakni 23.846 mahasiswa aktif dari berbagai fakultas dan program studi, jumlah yang cukup dapat bersaing dengan universitas swasta ternama lainnya di Yogyakarta seperti UMY 26.840 mahasiswa dan UII 23.655 mahasiswa, apalagi setelah pembangunan kampus 4 UAD selesai nanti akan lebih berpotensi semakin banyak kuota mahasiswa baru yang ditambah. Begitupula pada fakultas ekonomi dan bisnis UAD sendirikhususnya program studi Manajemen, jumlah kuota mahasiswa baru terus ditambah setiap tahunnya sejak UAD masih terakreditasi $B$ hingga akreditasi A seperti sekarang ini, hal tersebut mencerminkan tingginya minat mahasiswaakan karier pada bidang ekonomi manajemen.

Dalam perencanaan bidang karier tertentu memerlukan perhitungan yang matang, agar langkah proses pencapaian karier tersebut dapat lebih sistematis. Menurut Dessler (2009), pilihan karier merupakan proses yang penuh pertimbangan saat seseorang memiliki pemahaman mengenai keterampilan, pengetahuan, motivasi, dan karateristik pribadi lainnya, dan memantapkan rencana tindakan untuk mencapai tujuan yang lebih spesifik. Proses perencanaan karier tersebut akan membangun alternatifalternatif pilihan karier seseorang. Jadi, secara sederhana pilihan karier adalah suatu proses dari individu sebagai usaha mempersiapkan dirinya untuk memasuki tahapan yang berhubungan dengan pekerjaan. Dari pemaparan tersebut, maka bagi mahasiswa semester akhir, pilihan karier adalah hal yang penting dipertimbangkanm dimana ilmu pengetahuan yang dipelajari sudah lebih terkonsentrasi pada minat dari pilihan karier mahasiswa itu sendiri. Persepsi merupakan hal yang pentin dalam pengambilan keputusan pilihan karier seseorang. Persepsi adalah sebuah aktivitas berupa mengindra, mengintegrasikan, serta memberikan penilaian pada objek-objek fisik ataupun sosial. Pengindraan tersebut biasanya tergantung dari stimulus fisik dan sosial yang berada di dalam lingkungannya. Dari lingkungan ini lah yang akan diolah bersama dengan hal lainnya yang sudah dipelajari sebelumnya, baik berupa harapan, nilai, ingatan, sikap dan lainnya (Tarigan, 2015). 
Perbedaan persepsi dapat dipengaruhi oleh perubahan generasi manusia dari waktu ke waktu. Perbedaan generasi dalam dunia kerja menjadi salah satu isu yang selalu muncul dalam perkembangan manajemen sumber daya manusia. Generasi adalah sekelompok individu yang mengidentifikasi kelompoknya berdasarkan kesamaan tahun kelahiran, umur, lokasi, dan kejadian-kejadian dalam kehidupan, kelompok individu tersebut yang memiliki pengaruh signifikan dalam fase pertumbuhan mereka (Putra, 2016). Teori generasi di bagi menjadi 4 (empat) kelompok yakni, tradisionalis yakni mereka yang lahir antara tahun 1925 dan 1945, baby boomer yakni mereka yang lahir antara tahun 1946 dan 1964, Generasi $\mathrm{X}$ yakni mereka yang lahir tahun 1965 hingga tahun 1980, terakhir, Generasi Y yakni merupakan generasi terakhir yang lahir antara tahun 1981 hingga tahun 2000 (Putra, 2016). Berkaitan dengan pilihan karier, objek yang paling relevan untuk diteliti, yang sesuai dengan perkembangan zaman saat ini adalah mereka yang sedang berada pada fase generasi $\mathrm{Y}$, karena terdapat banyak pada usia ini yang sedang mempersiapkan diri untuk mencapai pilihan karier mereka, khususnya mahasiswa yang akan memasuki dunia kerja.

Generasi $\mathrm{Y}$ merupakan generasi yang lahir pada tahun 1981 hingga tahun 2000, merupakan generasi yang multikultural, memiliki kesukarelawanan yang tinggi, percaya diri, dan juga cerdas dalam teknologi (Prabowo, 2016). Faktorfaktor yang mempengaruhi persepsi generasi $\mathrm{Y}$ terhadap pilihan karier antara lain, pertimbangan pasar kerja (Harianti, 2017), motivasi karier (Kurniawan, 2014) dan pengaruh keluarga (Effendi, 2018), nilai sosial pekerjaan (Mulianto, 2014) dan career lifestyle (Susanti, 2014). Faktor-faktor tersebut itu lah yang dapat membentuk persepsi tersendiri dari generasi $\mathrm{Y}$ kaitannya dalam memutuskan pilihan karier. Ruang lingkup pilihan karier yang luas, menimbulkan seseorang bimbang dalam memilih suatu bidang karier tertentu. Hal tersebut banyak dirasakan para mahasiswa dari jurusan ekonomi dan bisnis, dimana ruang lingkup pilihan karier pada mahasiswa ekonomi yang luas dan universal.

Tujuan dari penelitian ini adalah: 1) untuk mengetahui pengaruh pertimbangan pasar kerja terhadap pilihan karier pada mahasiswa Program Studi Manajemen Universitas Ahmad Dahlan, 2) untuk mengetahui pengaruh motivasi karier terhadap pilihan karier pada mahasiswa Program Studi Manajemen Universitas Ahmad Dahlan, 3) untuk mengetahui pengaruh keluarga terhadap pilihan karier pada mahasiswa Program Studi Manajemen Universitas Ahmad Dahlan, 4) untuk mengetahui pengaruh nilai sosial pekerjaan terhadap pilihan karier pada mahasiswa Program Studi Manajemen Universitas Ahmad Dahlan, 5) untuk mengetahui pengaruh career lifestyle terhadap pilihan karier pada mahasiswa Program Studi Manajemen Universitas Ahmad Dahlan dan 6) untuk mengetahui pengaruh pertimbangan pasar kerja, motivasi karier, pengaruh keluarga, nilai sosial pekerjaan dan career lifestyle secara simultan terhadap pilihan karier pada mahasiswa Program Studi Manajemen Universitas Ahmad Dahlan.

\section{REVIEW LITERATUR DAN HIPOTESIS}

\section{Landasan Teori}

1. Pilihan Karir

Pilihan karier adalah suatu proses dari individu sebagai usaha mempersiapkan dirinya untuk memasuki tahapan yang berhubungan dengan pekerjaan (Dessler, 2009). 
2. Generasi Y (Millenial Generation)

Generasi Y merupakan generasi yang lahir pada tahun 1981 hingga tahun 2000, merupakan generasi yang multikultural, memiliki kesukarelawanan yang tinggi, percaya diri, dan juga cerdas dalam teknologi (Prabowo, 2016).

3. Persepsi

Persepsi adalah sebuah aktivitas berupa mengindra, mengintegrasikan, serta memberikan penilaian pada objekobjek fisik ataupun sosial. Pengindraan tersebut biasanya tergantung dari stimulus fisik dan sosial yang berada di dalam lingkungannya. Dari lingkungan ini lah yang akan diolah bersama dengan hal lainnya yang sudah dipelajari sebelumnya, baik berupa harapan, nilai, ingatan maupun sikap (Tarigan, 2015).

4. Pertimbangan Pasar Kerja Menurut Harianti (2017), pertimbangan pasar kerja merupakan salah satu hal yang menjadi bahan pertimbangan seseorang ketika memilih dan menentukan sebuah pekerjaan, karena setiap pekerjaan memiliki sebuah peluang serta kesempatan yang berbeda-beda.

5. Motivasi Karir

Motivasi karir adalah dorongan yang timbul dalam diri seseorang untuk senantiasa meningkatkan kemampuan pribadinya dalam rangka mencapai kedudukan, jabatan atau karir yang lebih baik dari sebelumnya (Abdillah, 2011).

\section{Pengaruh Keluarga}

Menurut Ahmadi (2009), keluarga merupakan kelompok primer yang paling penting di dalam masyarakat. Keluarga merupakan sebuah group yang terbentuk dari perhubungan laki-laki dan wanita, perhubungan yang mana sedikit banyak berlangsung lama untuk menciptakan dan membesarkan anakanak. Hasil penelitian Mulianto (2014), menyatakan bahwa yang memiliki pengaruh pada mahasiswa dalam menentukan pilihan untuk berkarier adalah motivasi karier dan pengaruh orang tua.

\section{Nilai Sosial Pekerjaan}

Menurut Mulianti (2014), nilai sosial pekerjaan adalah nilai yang berhubungan dengan lingkungan seperti bagaimana seseorang berinteraksi dengan orang lain dimana dilakukan untuk menunjukkan kemampuan yang dimiliki yang berkaitan dengan karier.

\section{Career Lifestyle}

Career lifestyle adalah pola gaya hidup yang membentuk kebutuhan dan nilai individu untuk mengintegrasikan kehidupan keluarga dan karir yang mempengaruhi keputusan karirnya (Susanti, 2014).

\section{Penelitian Terdahulu}

Harianti (2017) melakukan penelitian dengan judul pengaruh finansial, pertimbangan pasar kerja dan lingkungan keluarga terhadap minat menjadi akuntan publik. Hasilnya variabel penghargaan finansial, pertimbangan pasar kerja, motivasi karier berpengaruh terhadap pilihan karier mahasiswa.

Iswahyuni (2018) melakukan penelitian dengan judul analisis faktorfaktor yang mempengaruhi pemilihan karier menjadi akuntan publik. Hasil pengujian menunjukkan nilai sosial pekerjaan berpengaruh terhadap pemilihan karir mahasiswa akuntansi STIE AKA Semarang. 
Hipotesis

H1: Pertimbangan pasar kerja berpengaruh signifikan positif terhadap pilihan karier mahasiswa Program Studi Manajemen Universitas Ahmad Dahlan.

$\mathrm{H} 2$ : Motivasi karier berpengaruh signifikan positif terhadap pilihan karier mahasiswa Program Studi Manajemen Universitas Ahmad Dahlan.

H3: Keluarga berpengaruh signifikan positif terhadap pilihan karier mahasiswa Program Studi Manajemen Universitas Ahmad Dahlan.

H4: Nilai sosial pekerjaan berpengaruh signifikan positif terhadap pilihan karier mahasiswa Program Studi Manajemen Universitas Ahmad Dahlan.

H5: Career lifestyle berpengaruh signifikan terhadap pilihan karier mahasiswa Program Studi Manajemen Universitas Ahmad Dahlan.

H6: Pertimbangan pasar kerja, motivasi karier, pengaruh keluarga, nilai sosial pekerjaan dan career lifestyle secara simultan berpengaruh signifikan terhadap pilihan karier mahasiswa Program Studi Manajemen Universitas Ahmad Dahlan.

\section{METODE PENELITIAN}

\section{Populasi dan Sampel}

Populasi adalah wilayah generalisasi yang terdiri atas objek/subyek yang mempunyai kualitas dan karakteristik tertentu yang ditetapkan oleh peneliti untuk dipelajari dan kemudian ditarik kesimpulannya (Sugiyono, 2017).
Populasi dalam penelitian ini adalah mahasiswa Program Studi Manajemen Universitas Ahmad Dahlan angkatan 2015 dengan jumlah 364 mahasiswa.

Menurut Sugiyono (2017), sampel adalah bagian dari jumlah dan karakteristik yang dimiliki oleh populasi tersebut. Sampel dalam penelitian ini adalah sebagian mahasiswa Program Studi Manajemen Universitas Ahmad Dahlan angkatan 2015 dengan tingkat kesalahan $5 \%$. Penentuan jumlah sampel dari populasi dengan taraf kesalahan 5\% diambil dari penentuan jumlah sampel yang dikembangkan oleh Roscoe (Sugiyono, 2017), "bila dalam penelitian akan melakukan analisis dengan multivariate (korelasi atau regresi berganda), maka jumlah anggota sampel minimal 10 kali dari jumlah variabel yang diteliti". Jadi total sampel dalam penelitian ini minimal sebanyak 60 mahasiswa.

\section{Definisi Operasional}

1. Variabel Independen

a. Pertimbangan Pasar Kerja

Pertimbangan pasar kerja adalah pertimbangan yang berkaitan dengan seluruh kebutuhan dan persediaan tenaga kerja, atau seluruh permintaan dan penawaran dalam masyarakat dengan seluruh mekanisme yang memungkinkan adanya transaksi produktif diantara orang menjual tenaganya dengan pihak pengusaha yang membutuhkan tenaga tersebut (Harianti, 2017).

b. Motiviasi Karir

Motivasi karir adalah dorongan yang timbul dalam diri seseorang untuk senantiasa meningkatkan kemampuan pribadinya dalam rangka mencapai kedudukan, jabatan atau karir yang 
lebih baik dari sebelumnya (Abdillah, 2011).

c. Pengaruh Keluarga

Menurut Ahmadi (2009), keluarga adalah merupakan kelompok primer yang paling penting di dalam masyarakat. Keluarga merupakan sebuah group yang terbentuk dari perhubungan laki-laki dan wanita, perhubungan mana sedikit banyak berlansung lama untuk menciptakan dan membesarkan anak-anak.

d. Nilai Sosial Pekerjaan

Menurut Mulianto (2014) nilai sosial pekerjaan adalah nilai yang berhubungan dengan lingkungan seperti bagaimana seseorang berinteraksi dengan orang lain dimana dilakukan untuk menunjukkan kemampuan yang dimiliki yang berkaitan dengan karir.

e. Career Lifestyle

Career lifestyle adalah pola gaya hidup yang membentuk kebutuhan dan nilai individu untuk mengintegrasikan kehidupan keluarga dan karir yang mempengaruhi keputusan karirnya (Susanti, 2014).

2. Variabel Dependen

Pilihan karier adalah suatu proses dari individu sebagai usaha mempersiapkan dirinya untuk memasuki tahapan yang berhubungan dengan pekerjaan (Dessler, 2009).

\section{Uji Instrumen}

\section{Uji Validitas}

Uji validitas digunakan untuk mengukur sah atau tidaknya suatu kuesioner. Suatu kuesioner dikatakan valid jika pertanyaan pada kuesioner mampu untuk mengungkapkan sesuatu yang akan diukur, apakah pertanyaan dalam kuesioner yang telah kita buat betul-betul dapat mengukur apa yang hendak kita ukur (Adhila et.al., 2014). Alat ukur validitas dalam penelitian ini menggunakan Confirmatory Factor Analysis (CFA). Apabila dalam penelitian ini nilai loading factor lebih besar dari 0,5 maka dapat dikatakan valid (Sugiyono, 2017).

2. Uji Reliabilitas

Uji reliabilitas digunakan untuk mengukur suatu kuesioner yang merupakan indikator dari variabel atau konstruk. Suatu kuesioner dikatakan reliabel atau handal jika jawaban seseorang terhadap pernyataan adalah konsisten atau stabil dari waktu ke waktu (Adhila et.al., 2014). Suatu konstruk atau variabel dikatakan reliabel jika memberikan nilai Cronbanch Alpha > 0,60 (Adhila et.al., 2014).

\section{Teknik Analisis Data}

1. Analisis Regresi Berganda

Dalam peneitian ini, peneliti menggunakan analisis regresi berganda. Analisis ini dignakan untuk mengetahui pengaruh variabel independen terhadap variabel dependen, dengan rumus sebagai berikut:

Rumus: $\mathrm{Y}=\mathrm{a}+\mathrm{b} 1 \mathrm{X} 1+\mathrm{b} 2 \mathrm{X} 2+\mathrm{b} 3 \mathrm{X} 3+$ b4X4+ b5X5

Keterangan:

$\mathrm{Y}=$ Pilihan Karier

$\mathrm{A}=$ Konstanta

b1-b5= Koefisien regresi variabel independen

$\mathrm{X} 1=$ (pertimbangan pasar kerja)

$\mathrm{X} 2=$ (motivasi karier)

$\mathrm{X} 3=$ (pengaruh keluarga $)$

$\mathrm{X} 4=$ (motivasi karier)

$\mathrm{X} 5=$ (career lifestyle $)$ 


\section{Uji Hipotesis}

1. Uji Parsial (Uji T)

Uji T pada dasarnya menunjukkan seberapa jauh pengaruh satu variabel penjelas/independen secara individu dalam menerangkan variasi variabel dependen. Pengambilan keputusan berdasarkan perbandingan nilai $\mathrm{t}$ dan nilai kriteria sesuai dengan tingkat signifikansinya yang digunakan yaitu 0,05 . Kriteria penerimaan hipotesis dalam penelitian ini yaitu:

Jika tingkat signifikansi $<0,05$, maka hipotesis diterima

Jika tingkat signifikansi > 0,05, maka hipotesis ditolak

\section{Uji Simultan (Uji F)}

Untuk mengetahui signifikan atau tidaknya pengaruh variabel bebas terhadap variabel terikat secara simultan digunakan $\alpha$ sebesar $5 \%$. Kriteria penerimaan hipotesis dalam penelitian ini yaitu:

Jika signifikansi > alpha 0,05 maka hipotesis ditolak

Jika signifikansi < alpha 0,05 maka hipotesis diterima

\section{Uji Koefisien Determinasi}

Koefisien determinasi sering pula disebut dengan koefisien determinasi majemuk (multiple coefficient of determination). " $\mathrm{R} 2$ menjelaskan proporsi variasi dalam variabel terikat (Y) yang dijelaskan oleh variabel bebas (lebih dari satu variabel) secara bersama-sama" (Sugiyono, 2010). Persamaan regresi linear berganda semakin baik apabila nilai koefisien determinasi (R2) semakin besar (mendekati 1) dan cenderung meningkat nilainya sejalan dengan peningkatan jumlah variabel bebas.

\section{HASIL PENELITIAN DAN PEMBAHASAN}

\section{Hasil Analisis Responden}

Karateristik Responden

\begin{tabular}{|c|c|c|c|}
\hline \multicolumn{2}{|c|}{ Keterangan } & \multirow{2}{*}{$\begin{array}{c}\text { Frekuensi } \\
\text { (Orang) } \\
40 \text { mahasiswa }\end{array}$} & \multirow{2}{*}{$\begin{array}{c}\text { Persentase (\%) } \\
40 \%\end{array}$} \\
\hline Usia Responden & $18-21$ tahun & & \\
\hline & $22-25$ tahun & 60 mahasiswa & $60 \%$ \\
\hline & Jumlah & 100 mahasiswa & $100 \%$ \\
\hline \multirow[t]{3}{*}{ Jenis Kelamin } & Laki-Laki & 28 mahasiswa & $28 \%$ \\
\hline & Perempuan & 72 mahasiswa & $72 \%$ \\
\hline & Jumlah & 100 mahasiswa & $100 \%$ \\
\hline \multirow[t]{5}{*}{ Pilihan Karier } & $\begin{array}{c}\text { Perkantoran } \\
\text { (karyawan } \\
\text { swasta, PNS dll) } \\
\end{array}$ & 42 mahasiswa & $42 \%$ \\
\hline & $\begin{array}{l}\text { Jasa (guru,dosen } \\
\text { dll) }\end{array}$ & 4 mahasiswa & $4 \%$ \\
\hline & Wirausaha & 28 mahasiswa & $28 \%$ \\
\hline & Pekerjaan lainnya & 26 mahasiswa & $26 \%$ \\
\hline & Jumlah & 100 mahasiswa & $100 \%$ \\
\hline
\end{tabular}

Berdasarkan pada tabel di atas, dapat diketahui karakteristik responden, yaitu:

1. Responden yang mempunyai Umur 1821 tahun sebanyak 40 orang atau $40,0 \%$ dari total responden sebanyak 100 orang.

2. Responden yang mempunyai Umur 2225 tahun sebanyak 60 orang atau $60,0 \%$ dari total responden sebanyak 100 orang.

3. Responden yang berjenis kelamin lakilaki sebanyak 28 orang atau $28,0 \%$ dari total responden sebanyak 100 orang.

4. Responden yang berjenis kelamin perempuan sebanyak 72 orang atau $72,0 \%$ dari total responden sebanyak 100 orang. 
5. Responden dengan pilihan karier bidang perkantoran sebanyak 42 orangatau $42,0 \%$ dari total responden sebanyak 100 orang.

6. Responden dengan pilihan karier bidang jasa sebanyak 4 orang atau 4,0\%dari total responden sebanyak 100 orang.

7. Responden dengan pilihan karier sebagai wirausaha sebanyak 28 orangatau $28,0 \%$ dari total responden sebanyak 100 orang.

8. Responden dengan pilihan karier pada bidang pekerjaan lainnya sebanyak 26 orang atau $46,0 \%$ dari total responden sebanyak 100 orang.

\section{Hasil Penelitian}

1. Hasil Uji Validitas

Hasil Validitas Semua Variabel

\begin{tabular}{|c|c|c|c|c|c|c|c|}
\hline Item & $\begin{array}{c}\text { Pertimbangan } \\
\text { Pasar Kerja }\end{array}$ & $\begin{array}{c}\text { Motivasi } \\
\text { Karier }\end{array}$ & $\begin{array}{l}\text { Pengaruh } \\
\text { Keluarga }\end{array}$ & $\begin{array}{c}\text { Nilai } \\
\text { Sosial } \\
\text { Pekerjaan }\end{array}$ & $\begin{array}{c}\text { Career } \\
\text { Lifestyle }\end{array}$ & $\begin{array}{l}\text { Pilihan } \\
\text { Karier }\end{array}$ & $\begin{array}{c}\text { Keter } \\
\text { anga } \\
\text { n }\end{array}$ \\
\hline $\begin{array}{c}\text { PPK. } \\
1.2 \\
\end{array}$ & 0,645 & & & & & & Valid \\
\hline $\begin{array}{c}\text { PPK. } \\
2.1\end{array}$ & 0,763 & & & & & & \begin{tabular}{|l|l} 
Valid \\
\end{tabular} \\
\hline $\begin{array}{c}\text { PPK. } \\
2.2\end{array}$ & 0,816 & & & & & & Valid \\
\hline $\begin{array}{c}2.2 \\
\text { PPK. } \\
4.2\end{array}$ & 0,808 & & & & & & Valid \\
\hline $\begin{array}{c}\text { PPK. } \\
5.1 \\
\end{array}$ & 0,816 & & & & & & Valid \\
\hline $\begin{array}{c}\text { MK. } \\
1.1 \\
\end{array}$ & & 0,746 & & & & & Valid \\
\hline $\begin{array}{l}\text { MK. } \\
1.2\end{array}$ & & 0,689 & & & & & Valid \\
\hline $\begin{array}{c}\text { MK. } \\
2.1\end{array}$ & & 0,858 & & & & & Valid \\
\hline \begin{tabular}{|c|} 
MK. \\
2.2
\end{tabular} & & 0,653 & & & & & Valid \\
\hline $\begin{array}{c}\text { MK. } \\
4.1 \\
\end{array}$ & & 0,767 & & & & & Valid \\
\hline \begin{tabular}{|c|} 
MK. \\
4.2
\end{tabular} & & 0,769 & & & & & Valid \\
\hline $\begin{array}{c}\text { PKL. } \\
2.1\end{array}$ & & & 0,771 & & & & Valid \\
\hline $\begin{array}{c}\text { PKL. } \\
2.2 \\
\end{array}$ & & & 0,763 & & & & Valid \\
\hline $\begin{array}{c}\text { PKL. } \\
3.1 \\
\end{array}$ & & & 0,761 & & & & Valid \\
\hline $\begin{array}{c}\text { PKL. } \\
3.2\end{array}$ & & & 0,772 & & & & Valid \\
\hline $\begin{array}{c}\text { PKL. } \\
4.1\end{array}$ & & & 0,647 & & & & Valid \\
\hline $\begin{array}{c}\text { NSP. } \\
1.1\end{array}$ & & & & 0,766 & & & Valid \\
\hline $\begin{array}{c}\text { NSP. } \\
1.2\end{array}$ & & & & 0,683 & & & \begin{tabular}{|l} 
Valid \\
\end{tabular} \\
\hline
\end{tabular}

\begin{tabular}{|c|c|c|c|c|c|c|c|}
\hline Item & \begin{tabular}{|l|} 
Pertimbangan \\
Pasar Kerja
\end{tabular} & \begin{tabular}{|c|} 
Motivasi \\
Karier
\end{tabular} & \begin{tabular}{|l|} 
Pengaruh \\
Keluarga
\end{tabular} & $\begin{array}{c}\text { Nilai } \\
\text { Sosial } \\
\text { Pekerjaan }\end{array}$ & \begin{tabular}{|c|} 
Career \\
Lifestyle
\end{tabular} & $\begin{array}{l}\text { Pilihan } \\
\text { Karier }\end{array}$ & $\begin{array}{c}\text { Keter } \\
\text { anga } \\
\text { n } \\
\end{array}$ \\
\hline $\begin{array}{c}\text { NSP. } \\
2.1\end{array}$ & & & & 0,734 & & & Valid \\
\hline $\begin{array}{c}\text { NSP. } \\
2.2\end{array}$ & & & & 0,653 & & & Valid \\
\hline $\begin{array}{c}\text { NSP. } \\
3.2\end{array}$ & & & & 0,638 & & & Valid \\
\hline $\begin{array}{c}\text { NSP. } \\
4.2\end{array}$ & & & & 0,685 & & & Valid \\
\hline $\begin{array}{l}\text { CL. } \\
1.1 \\
\end{array}$ & & & & & 0,606 & & Valid \\
\hline $\begin{array}{l}\text { CL. } \\
2.1\end{array}$ & & & & & 0,654 & & Valid \\
\hline $\begin{array}{l}\text { CL. } \\
2.2 \\
\end{array}$ & & & & & 0,744 & & Valid \\
\hline $\begin{array}{l}\text { CL. } \\
3.1 \\
\end{array}$ & & & & & 0,809 & & Valid \\
\hline $\begin{array}{l}\text { CL. } \\
3.2\end{array}$ & & & & & 0,713 & & Valid \\
\hline $\begin{array}{l}\text { PKR } \\
.1 .1 \\
\end{array}$ & & & & & & 0,865 & Valid \\
\hline $\begin{array}{l}\text { PKR } \\
.1 .2 \\
\end{array}$ & & & & & & 0,796 & \begin{tabular}{|l|} 
Valid \\
\end{tabular} \\
\hline $\begin{array}{l}\text { PKR } \\
.2 .1\end{array}$ & & & & & & 0,872 & Valid \\
\hline $\begin{array}{l}\text { PKR } \\
.2 .2 \\
\end{array}$ & & & & & & 0,873 & Valid \\
\hline $\begin{array}{l}\text { PKR } \\
.3 .1 \\
\end{array}$ & & & & & & 0,793 & Valid \\
\hline $\begin{array}{l}\text { PKR } \\
.4 .1 \\
\end{array}$ & & & & & & 0,505 & Valid \\
\hline $\begin{array}{l}\text { PKR } \\
.4 .2 \\
\end{array}$ & & & & & & 0,648 & Valid \\
\hline
\end{tabular}

Jadi, dari 48 butir pernyataan pada keseluruhan variabel hanya memiliki 34 butir pernyataan yang dapat dikatakan valid sesuai standar yang memiliki nilai factor loading $\geq$ 
0,50 dan tidak terdapat nilai negatif seperti pada tabel di atas.

2. Hasil Uji Reliabilitas

Hasil Uji Reliabilitas

\begin{tabular}{|c|c|c|}
\hline Variabel & Cronbach's Alpha & Keterangan \\
\hline $\begin{array}{c}\text { Pertimbangan Pasar } \\
\text { Kerja (X1) }\end{array}$ & 0,824 & Reliabel \\
\hline Motivasi Karier (X2) & 0,843 & Reliabel \\
\hline $\begin{array}{c}\text { Pengaruh Keluarga } \\
(\mathrm{X} 3)\end{array}$ & 0,794 & Reliabel \\
\hline $\begin{array}{c}\text { Nilai Sosial Pekerjaan } \\
(\mathrm{X} 4)\end{array}$ & 0,781 & Reliabel \\
\hline Career Lifestyle (X5) & 0,742 & Reliabel \\
\hline Pilihan Karier (Y) & 0,879 & Reliabel \\
\hline
\end{tabular}

Dari tabel di atas dapat diketahui bahwa semua variabel dinyatakan reliabel karena nilai Cronbach"s Alpha tiap variabel > 0,60.

3. Hasil Uji Regresi Linier Berganda Hasil Uji Regresi Linear Berganda

\begin{tabular}{|c|c|}
\hline Model & Unstandardized Coefficient \\
\cline { 2 - 2 } & B \\
\hline (Constanta) & $-0,483$ \\
Pertimbangan Pasar Kerja (X1) & 0,060 \\
Motivasi Karier (X2) & 0,723 \\
Pengaruh Keluarga (X3) & 0,072 \\
Nilai Sosial Pekerjaan (X4) & 0,231 \\
Career Lifestyle (X5) & $-0,003$ \\
\hline
\end{tabular}

Berdasarkan hasil perhitungan dengan menggunakan program IBM SPSS Statistics 20 dapat diketahui persamaan regresi berganda linear yaitu sebagai berikut:

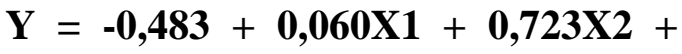
$0,072 X 3+0,231 X 4-0,003 X 5$

Dari hasil persamaan regresi linear berganda tersebut, dapat diinterpretasikan sebagai berikut:

a. Nilai koefisien regresi pilihan karier (Y) sebesar -0,483 merupakan nilai konstanta, jika X1, X2, X3, X4 dan X5 dianggap 0, maka pilihan karier nilainya sebesar $-0,483$.

b. Nilai koefisien regresi pertimbangan pasar kerja (X1) sebesar 0,060 bertanda positif, artinya semakin tinggi pertimbangan pasar kerja mahasiswa maka, pilihan kariernya juga semakin yakin/tinggi.

c. Nilai koefisien regresi motivasi karier (X2) sebesar 0,723 bertanda positif, artinya semakin tinggi motivasi karier mahasiswa maka, pilihan kariernya juga semakin yakin/tinggi.

d. Nilai koefisien regresi pengaruh keluarga (X3) sebesar 0,072 bertanda positif, artinya semakin tinggi pengaruh keluarga maka, pilihan kariernya juga semakin yakin/tinggi.

e. Nilai koefisien regresi nilai sosial pekerjaan (X4) sebesar 0,231 dan bertanda positif, artinya semakin tinggi nilai sosial pekerjaan mahasiswa maka, pilihan kariernya juga semakin yakin/tinggi.

f. Nilai koefisien regresi career lifestyle (X5) sebesar -0,003 dan bertanda negatif, artinya semakin tinggi career lifestylemahasiswa maka, pilihan kariernya semakin kurang yakin/rendah. 
4. Hasil Uji Parsial (Uji T)

Hasil Uji Signifikasi Parsial (Ujit)

\begin{tabular}{|c|c|}
\hline \multirow{2}{*}{ Variabel } & Hasil Uji \\
\cline { 2 - 2 } & Signifikansi \\
\hline Pertimbanga Pasar Kerja $(\mathrm{X} 1)$ & 0,428 \\
\hline Motivasi Karier $(\mathrm{X} 2)$ & 0,000 \\
\hline Pengaruh Keluarga $(\mathrm{X} 3)$ & 0,201 \\
\hline Nilai Sosial Pekerjaan(X4) & 0,005 \\
\hline Career Lifestyle $(\mathrm{X} 5)$ & 0,954 \\
\hline
\end{tabular}

Berdasarkan tabel di atas, maka hasil uji $\mathrm{t}$ pada penelitian ini dapat dijelaskan sebagai berikut:

a. Variabel Pertimbangan Pasar Kerja

Dilihat dari nilai signifikansi pada tabel di atas, diketahui bahwa nilai signifikansi yang diperoleh sebesar 0,428 , hal ini menunjukkan bahwa nilai signifikansi $0,428>0,05$, maka dapat disimpulkan bahwa pertimbangan pasar kerja tidak berpengaruh signifikan positif terhadap pilihan karier mahasiswa Program Studi Manajemen Universitas Ahmad Dahlan, yang berarti H1 ditolak.

b. Variabel Motivasi Karier

Dilihat dari nilai signifikansi pada tabel di atas, diketahui bahwa nilai signifikansi yang diperoleh sebesar 0,000, hal ini menunjukkan bahwa nilai signifikansi $0,000<0,05$, maka dapat disimpulkan bahwa motivasi karier berpengaruh signifikan positif terhadap pilihan karier mahasiswa Program Studi Manajemen Universitas Ahmad Dahlan, yang berarti $\mathrm{H} 2$ diterima.

c. Variabel Pengaruh Keluarga

Dilihat dari nilai signifikansi pada tabel di atas, diketahui bahwa nilai signifikansi yang diperoleh sebesar 0,201 , hal ini menunjukkan bahwa nilai signifikansi 0,201 >0,05, maka dapat disimpulkan bahwa pengaruh keluarga tidak berpengaruh signifikan positif terhadap pilihan karier mahasiswa Program Studi Manajemen Universitas Ahmad Dahlan, yang berarti H3 ditolak.

d. Variabel Nilai Sosial Pekerjaan

Dilihat dari nilai signifikansi pada tabel di atas, diketahui bahwa nilai signifikansi yang diperoleh sebesar 0,005, hal ini menunjukkan bahwa nilai signifikansi $0,005<0,05$, maka dapat disimpulkan bahwa nilai sosial pekerjaan berpengaruh signifikan positif terhadap pilihan karier mahasiswa Program Studi Manajemen Universitas Ahmad Dahlan, yang berarti $\mathrm{H} 4$ diterima.

e. Variabel Career Lifestyle

Dilihat dari nilai signifikansi pada tabel di atas, diketahui bahwa nilai signifikansi yang diperoleh sebesar 0,954, hal ini menunjukkan bahwa nilai signifikansi $0,954>0,05$, maka dapat disimpulkan bahwa career lifestyle tidak berpengaruh signifikan terhadap pilihan karier mahasiswa Program Studi Manajemen Universitas Ahmad Dahlan, yang berarti H5 ditolak.

\section{Hasil Uji Simultan (Uji F)} Hasil Uji F

\begin{tabular}{|c|c|}
\hline F & Signifikasi \\
\hline 63,717 & 0,000 \\
\hline
\end{tabular}

Berdasarkan hasil uji simultan pada tabel di atas, diketahui bahwa $\mathrm{F}$ hitung sebesar 63,717 dan nilai signifikansi sebesar $0,000<0,05$ sehingga dapat disimpulkan bahwa pertimbangan pasar kerja (X1), motivasi karier (X2), pengaruh keluarga (X3), nilai sosial pekerjaan (X4), career lifestyle (X5) secara simultan berpengaruh signifikan terhadap pilihan karier (Y), yang berarti H6 diterima. 
6. Hasil Uji Koefisien Determinasi

Hasil Uji Koefisien Determinasi

\begin{tabular}{|c|c|}
\hline Model & R square \\
\hline 1 & 0,772 \\
\hline
\end{tabular}

Berdasarkan tabel di atas, diketahui bahwa nilai $\mathrm{R}$ square sebesar 0,772. Hal ini dapat diartikan bahwa sumbangai pengaruh variabel independen (pertimbangan pasar kerja (X1), motivasi karier (X2), pengaruh keluarga (X3), nilai sosial pekerjaan (X4), career lifestyle(X5)) terhadap variabel dependen (pilihan karier (Y)), sebesar 77,2\%, sedangkan sisanya $22,8 \%$ dijelaskan oleh variabel lain yang tidak diteliti.

\section{Pembahasan}

1. Pernyataan hipotesis pertama bahwa variabel pertimbangan pasar kerja (X1) berpengaruh signifikan positif terhadap pilihan karier mahasiswa Program Studi Manajemen Universitas Ahmad Dahlan tidak terbukti dalam penelitian ini. Karena responden dalam penelitian ini sebagian masih berusia 18-21 tahun maka belum memliliki banyak pengalaman mengenai bagaimana pertimbangan pasar kerja yang akan mereka pertimbangkan. Hasil penelitian ini sesuai dengan hasil penelitian Iswahyuni (2018) yang menyatakan bahwa pertimbangan pasar kerja tidak berpengaruh signifikan terhadap pilihan karier.

2. Pernyataan hipotesis ke dua bahwa variabel motivasi karier (X2) berpengaruh signifikan positif terhadap pilihan karier mahasiswa Program Studi Manajemen Universitas Ahmad Dahlan terbukti dalam penelitian ini. Karena seseorang yang memiliki motivasi karier dalam pilihan kariernya, ia cenderung akan berusaha untuk dapat mencapainya. Hasil penelitian ini sesuai dengan hasil penelitian Kurniawan (2014) yang menyatakan bahwa motivasi karier berpengaruh signifikan terhadap pilihan karier.

3. Pernyataan hipotesis ke tiga bahwa variabel pengaruh keluarga (X3) berpengaruh signifikan positif terhadap pilihan karier mahasiswa Program Studi Manajemen Universitas Ahmad Dahlan tidak terbukti dalam penelitian ini. Karena di era global sekarang ini khusunya orang tua generasi millennial telah banyak menyadari bahwa anakanak sekarang sebaiknya dibebaskan untuk memilih bidang karier yang mereka sukai sesuai bakat dan minat mereka sehingga orang tua tidak banyak memberi pengaruh dalam pilihan karier anak. Hasil penelitian ini sesuai dengan hasil penelitian Harianti (2017) yang menyatakan bahwa pengaruh keluarga tidak berpengaruh signifikan terhadap pilihan karier.

4. Pernyataan hipotesis ke empat bahwa variabel nilai sosial pekerjaan $(\mathrm{X} 4)$ berpengaruh signifikan positif terhadap pilihan karier mahasiswa Program Studi Manajemen Universitas Ahmad Dahlan terbukti dalam penelitian ini. Karena di Indonesia sendiri sampai saat ini masih menjunjung tinggi nilai-nilai sosial di dalam kehidupan bermasyarakat, hal bersebut membuat seseorang juga mempertimbangkan nilai-nilai sosial dalam memlilih suatu bidang karier. Hasil penelitian ini sesuaidengan hasil penelitian Mulianto (2014) yang menyatakan bahwa nilai sosial pekerjaan berpengaruh signifikan terhadap pilihan karier.

5. Pernyataan hipotesis ke lima bahwa variabel career lifestyle

(X5) 
berpengaruh signifikan terhadap pilihan karier mahasiswa Program Studi Manajemen Universitas Ahmad Dahlan tidak terbukti dalam penelitian ini. Karena di Indonesia sendiri belum banyak perusahaan atau instansi yang dapat memenuhi tuntutan generasi millennialdengan prosedur dan sistem kerja yang sesuai dengan gaya hidup millennial. Hasil penelitian ini sesuai dengan hasil penelitian Widjaja (2013) yang menyatakan bahwa career lifestyle tidak berpengaruh signifikan terhadap pilihan karier.

6. Pernyataan hipotesis ke enam bahwa variabel pertimbangan pasar kerja, motivasi karier, pengaruh keluarga, nilai sosial pekerjaan dan career lifestyle secara simultan berpengaruh signifikan terhadap pilihan karier mahasiswa Program Studi Manajemen Universitas Ahmad Dahlan terbukti dalam penelitian ini.

\section{KESIMPULAN DAN SARAN}

\section{Kesimpulan}

1. Pertimbangan pasar kerja tidak berpengaruh signifikan positif terhadap pilihan karier mahasiswa Program Studi Manajemen Universitas Ahmad Dahlan.

2. Motivasi karier berpengaruh signifikan positif terhadap pilihan karier mahasiswa Program Studi Manajemen Universitas Ahmad Dahlan.

3. Keluarga tidak berpengaruh signifikan positif terhadap pilihan karier mahasiswa Program Studi Manajemen Universitas Ahmad Dahlan.

4. Nilai sosial pekerjaan berpengaruh signifikan positif terhadap pilihan karier mahasiswa Program Studi Manajemen Universitas Ahmad Dahlan.

5. Career Lifestyle tidak berpengaruh signifikan terhadap pilihan karier mahasiswa Program Studi Manajemen Universitas Ahmad Dahlan.

6. Pertimbangan pasar kerja, motivasi karier, pengaruh keluarga, nilai sosial pekerjaan dan career lifestyle secara simultan berpengaruh signifikan terhadap pilihan karier mahasiswa Program Studi Manajemen Universitas Ahmad Dahlan.

\section{Saran}

1. Program Studi Manajemen Universitas Ahmad Dahlan sebaiknya melengkapi fasilitas yang dapat menyalurkan pilihan karier mahasiswa sebagai wadah pelatihan dan praktik yang dapat di manfaatkan mahasiswa untuk mengasah kemampuan di bidang karier yang diminati.

2. Peneliti selanjutnya hendaknya membuat pentanyaan pada kuesioner yang lebih mudah dipahami responden agar tidak banyak item kuesioner yang tidak valid.

\section{DAFTAR PUSTAKA}

Adhila, Fitroh, Dyah Fitriani, dan Deny Ismanto. (2014). Petunjuk Praktikum Statistik 2. Yogyakarta: Universitas Ahamd Dahlan.

Abdilah, Elia. (2011). Pengeruh motivasi kualitas dan motivasi karier terhadap minat mahasiswa akuntansi untuk mengikuti pendidikan profesi akuntansi. EJournal. (Agustus) hal 12-29.

Ahmadi, Abu. (2009). Psikologi Umum. Edisi Revisi 2009. Jakarta: PT. Rineka Cipta.

Dessler, Gary. (2009). Manajemen Sumber Daya Manusia. Jakarta: PT. Macanan Jaya Cemerlang. 
Effendi, Liria S. (2018). Faktor-Faktor yang Memepengaruhi Pilihan Karier Mahasiswa Akuntansi di Fakultas Ekonomi dan Bisnis Universitas Islam Malang. Jurnal Ekonomi. Vol 7, No.08 (Agustus) hal. 39-51.

Harianti, Sarli S. (2017). Pengaruh finansial, pertimbangan pasar kerja dan lingkungan keluarga terhadap minat menjadi akuntan publik. Ejurnal Akuntansi. (Juni) hal. 4-6.

Iswahyuni, Yetti. 2018. Analisis FaktorFaktor yang Mempengaruhi Pemilihan Karier Menjadi Akuntan Publik. Jurnal Akuntansi. Vol 5 No. 1 (Januari) hal 9-39.

Kurniawan, Adhitya R. (2014). Pengaruh motivasi karier, motivasi ekonomi dan motivasin gelar terhadap minal mahasiswa akuntasi mengikuti pendidikan profesi akuntansi. $E$ Jurnal Akuntansi. (Oktober) hal.1128.

Mulianto, Stella F dan Yenni Mangoting. (2014). Faktor-faktor yang mempengaruhi pilihan karier mahasiswa akuntasi sebagai konsultan pajak. E-Journal Akuntansi. Vol 4, No 2, hal 3-5.

Prabowo, Anita., dan Pranawa Putranta. (2016). Persepsi Generasi Y Terhadap Pilihan Karier di Perusahaan Publik. Modus. Vol.28 (Januari), hal. 71-86.

Putra, Yanuar S. (2016). Teori Perbedaan Generasi. E-Journal. Vol 9 No. 18 hal. 123-134.

Sugiyono. (2010). Metode Penelitian Bisnis. Bandung : Alfabeta.

Sugiyono. (2017). Metode Penelitian Kuantitatif Kualitatif dan $R \& D$. Bandung: Alfabeta.

Susanti, Rinda dan Adi Respati. (2014). Perbedaan Jangkar Karier pada
Karier Generasi X dan Generasi Y. Jurnal Psikologi. (Oktober) hal 1.

Tarigan, Muhammad Iyyas. (2015). Faktor-Faktor yang mempengeruhi pilihankarier mahasiswa akuntasi sebagai editor pemerintahan. Jurnal Ekonomi. Vol.2 No.2 (Oktober) hal 2-7.

Widjaja, Mitha Novita. (2013). Faktorfaktor yang mempengaruhi pilihan karier sebagai Akuntan Publik. Jurnal Ekonomi. 